Journal of Engineering and Applied Sciences 14 (8): 2582-2587, 2019

ISSN: 1816-949X

(C) Medwell Journals, 2019

\title{
Utilization of Construction Waste to Developing an Abrasive Materials
}

\author{
Zainab M. Sabaa and Besma M. Fahad \\ Department of Materials Engineering, College of Engineering, Mustansiriyah University, \\ Baghdad, Iraq
}

\begin{abstract}
The waste resulting from construction and demolition process increased greatly in the last few decades resulting in the highest percentage of wastes. Using waste to produce artificial abrasives be one of the options to preserve the nonrenewable materials and minimize cost. In this study, the waste of building brick and glazed ceramic tiles were used to develop a bonding abrasive in form of the particulate composite using epoxy resin as a matrix. The waste of the two materials was crushed to obtain grits of $150,300,1200 \mu \mathrm{m}$ sizes. Hardness and wear rate were investigated for the abrasive composite specimens which carried out under different conditions that emulate the abrasives working conditions, i.e., the heat results from friction causing post cure to the polymer beside the effect of coolant. The highest hardness results along with low wear are shown by glazed ceramic tiles waste. It can be concluding that each of the post-cure and room temperature conditions gives the best results for both materials whilst the post-cure and immersion together possess the poorest results.
\end{abstract}

Key words: Specimens, polymer, glazed, hardness, materials whilst, conditions

\section{INTRODUCTION}

Now a days there are a lot of unwanted materials which emerge from households or during the production process by manufacturers which regarded as waste. The highest percentage of wastes throughout worldwide resulting from construction wastes (Taherzadeh and Richards, 2015; Zimbili et al., 2014). These waste generally disposed of in landfill sites. In the world, large quantities of ceramic waste are generated (Rambaldi et al., 2007; Kulovana et al., 2016). These wastes contribute the highest percentage of wastes within the construction wastes (Zimbili et al., 2014). Domestic ceramics pottery, porcelain, tiles and structural and refractory bricks are all in this category. Also, the ceramic industry is one of the contributors to increase these waste in the form of scrap (Kulovana et al., 2016; Martin, 2006). In ceramic tile production, due to various reasons, unsold fired products come out which are reject tiles (Zimbili et al., 2014; Rambaldi et al., 2007; Kulovana et al., 2016; Martin, 2006; Ay and Unal, 2000). There is also, the products which are refused because of commercial reasons. In addition, to this there is the waste produced from an demolition of structures such as brickbats, broken ceramic tile (Kulovana et al., 2016; Martin, 2006; Ay and Unal, 2000; Sekar et al., 2011). These discarded materials, most of which cannot be recycled within the plant, these residues cause both environmental impact and an increasing of the industrial running costs (Rambaldi et al., 2007;
Kulovana et al., 2016). The current option for disposal of these wastes is landfill which is due to lack knowledge and experience in using ceramic wastes in construction. People have started searching for suitable alternative materials which could be used either as an additive or as a partial replacement to preserve the existing natural resources to the possible extent, for the future generation. that lead to the recycling of waste which involves environmental (Zimbili et al., 2014; Rambaldi et al., 2007; Kulovana et al., 2016; Martin, 2006; Ay and Unal, 2000). Aspects that partly solves the disposal problem and reduces the consumption of natural raw materials (Rambaldi et al., 2007). And to ensure that waste is recovered without endangering human health and without using processes or methods which could harm the environment many of these waste substances can be reused as a resource for an industry processing them to produce a marketable product (Williams, 2005; Awange and Kyalo, 2013) and many manufactured products require machining at some stage of their production sequence. The machining industry entered new covenant by the development of new tool materials. In abrasion machining promising composite material for the production of abrasive tools has been obtained (El-Hofy, 2013; Shumyacher et al., 2017). A wide range of abrasives are being used to machining various components. Abrasives ranging from the economic verses of aluminium oxide to the likes of super-abrasives such as cubic boron nitride and the expensive diamond grains

Corresponding Author: Zainab M. Sabaa, Department of Materials Engineering, College of Engineering, Mustansiriyah University, Baghdad, Iraq 
which characterized by its versatility and capability of achieving the highest accuracy and surface quality in the most economical way (El-Hofy, 2013; Bhowmik and Naik, 2018). Since, there are excess stocks and defective products which generate a large volume of waste outputs in the ceramic industry. The chemical and mechanical characteristics of these wastes could allow their use as raw material for the different application such as in abrasive materials production (Silvestre et al., 2013). Many researchers have studied the reuse of brick and ceramic waste. Demir and Orhan (2003) studied the addition of waste-brick material in brick production. As a way to re-use the brick waste. Investigated the effects of recycling of waste brick material on the durability and mechanical properties of the bricks were. Found that waste brick additives decreased plasticity of the mixture and decrease the drying shrinkage (Demir and Orhan, 2003). Silvestre et al. (2013) investigated the possibility of using ceramic stoneware tile wastes as an aggregate replacement in hot bituminous open graded wearing courses. Resistance to plastic deformation produced by Recycled ceramic aggregates (Silvestre et al., 2013). Very little work has been done by researchers to reuse the waste materials as abrasives. Recently, Obot et al. (2017) studied the abrasive properties of periwinkle shell grains of different grit sizes with the polyester resin as a binding. The test results of this developed composite show an increase in hardness and compressive strength for the periwinkle/polyester resin composite with an increase in the concentration of resin (Obot et al., 2017). From the above-mentioned literature, it is understood that there are tremendous potentials of used brick and ceramic tiles wastes for different applications.

\section{MATERIALS AND METHODS}

Experimental details: In order to form the abrasive composite specimens the waste of common standard brick samples was collecting from the damaged brick in construction sites and the waste of ceramic wall tiles was obtained from demolition building in Iraq, Baghdad. This waste is used as reinforcement in the composite samples while a thermosetting polymer (epoxy resin a low viscosity resin of density of $1.1(\mathrm{~kg} / \mathrm{L}))$ was used as a binding material (the matrix) in the specimens, since, it has a good adhesion property and mechanical properties along with moderate cost compared to other polymer resins. The formation of epoxy consist of two components first is the resin and second is the hardener which is used to harden the material, the hardener was mixed in the resins prior to reinforcement for about $5 \mathrm{~min}$ to make sure that a good homogeneity is obtained.

Specimens preparation: Two types of waste were used to make the abrasive composite samples the waste was first cleaned to get rid of any unwanted foreign materials, to obtain a powdered waste from brick and glazed ceramic tiles two processes of crushing were used first crushed manually giving to large sized pieces than a jaw crusher where used. The last step in preparing the powder is the sieving which was done by using a set of sieves with the mesh of 1200,300 and $150 \mu \mathrm{m}$ sizes in diameter. In order to formulate the specimens, the hand lay-up technique was used two different types of particulate composite specimens were prepared as abrasives samples. With 1200,300 and $150 \mu \mathrm{m}$ size that used separately to produce specimens for each type. To shape the specimens a $30 \mathrm{~mm}$ height and $12 \mathrm{~mm}$ diameter cylindrical mould were used. A mixture of 25 and $75 \%$ by volume of epoxy resin and brick waste or ceramic tile waste, respectively were mixed for about $3 \mathrm{~min}$. As soon as a homogenous mixture obtained it manually pressed tightly in the cylindrical mould to reduce the porosity in the specimens which then cure at room temperature for about $24 \mathrm{~h}$ before removing from the mould and left for a week to gain the complete strength before testing.

Wear test: The mechanical behaviour of particulate waste filled epoxy resin composites had been studied in dry sliding condition. and carried out on pin-on-disc wear test as per ASTM G 99. The wear test conducted at room temperature under sliding distance (2827) $\mathrm{m}$, for a track radius of $0.06 \mathrm{~m}$ and normal load $5 \mathrm{~N}$ for $15 \mathrm{~min}$. The cylindrical pin specimens of $12 \mathrm{~mm}$ diameter and $30 \mathrm{~mm}$ length were tested against a disc made of stainless steel $(9269 \mathrm{HB})$. The specimen was held stationary and the disc was rotated at 500 RPM while a normal force was applied. The surface of the disc was cleaned using cotton with acetone before the test the schematic diagram of the pin-on-disc apparatus is shown in Fig. 1. The samples are weighed before and after the experiments to an accuracy of $0.0001 \mathrm{~g}$ electronic balance. The specific wear rate calculated from the two weight readings according to the equation:

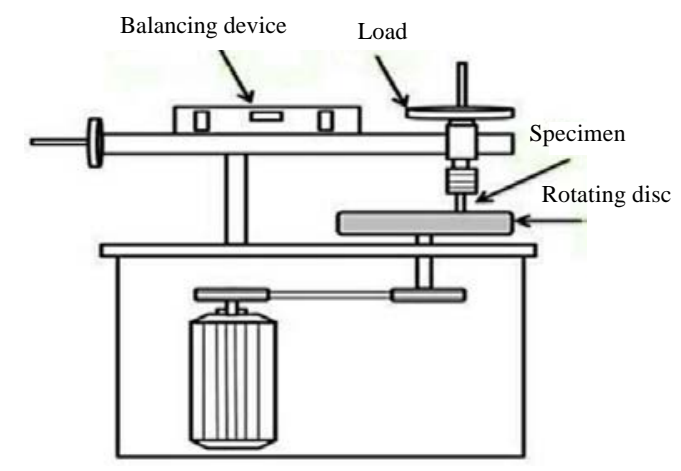

Fig. 1: The schematic diagram of the pin-on-disc apparatus 
(a)

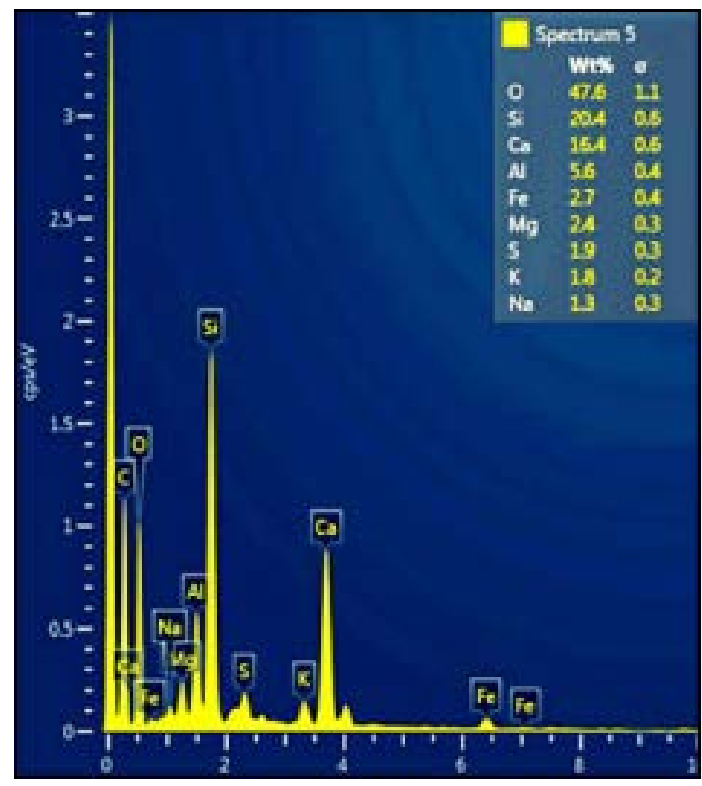

(b)

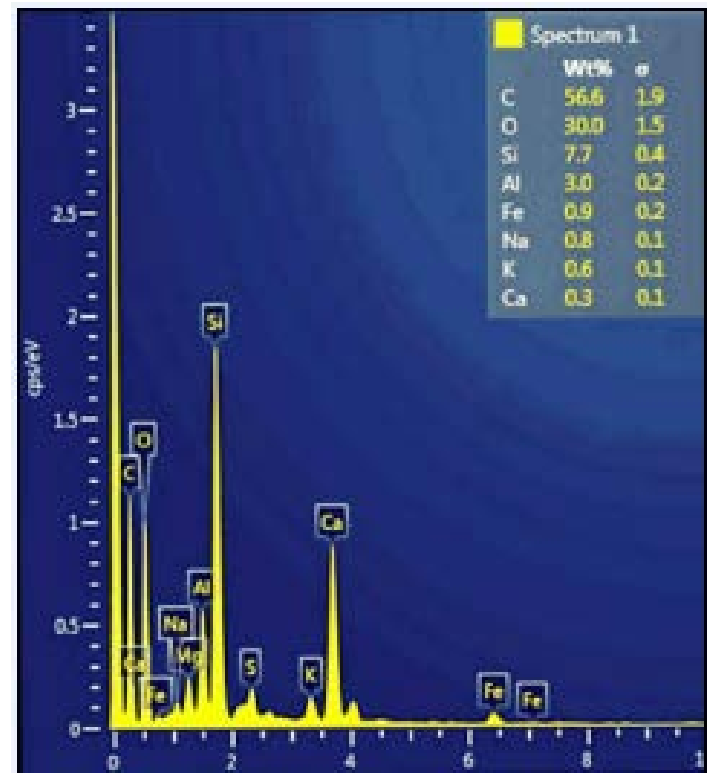

Fig. 2: EDS of the surface for: a) Brick and b) Glazed ceramic tile composites specimens

(a)

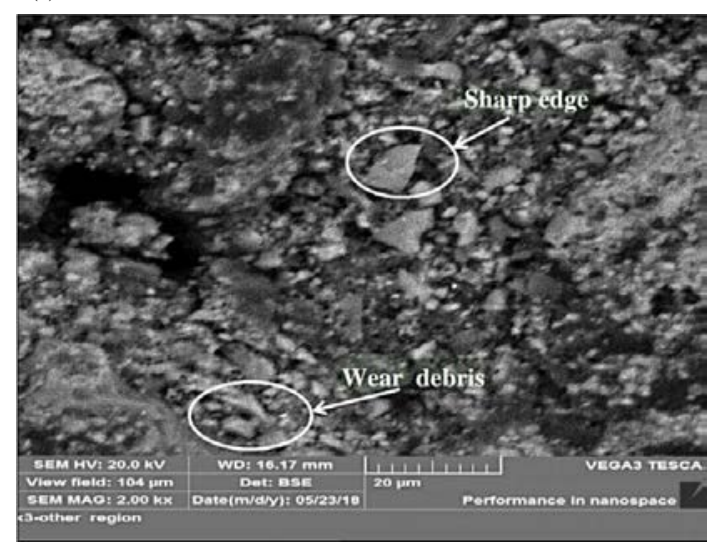

(b)

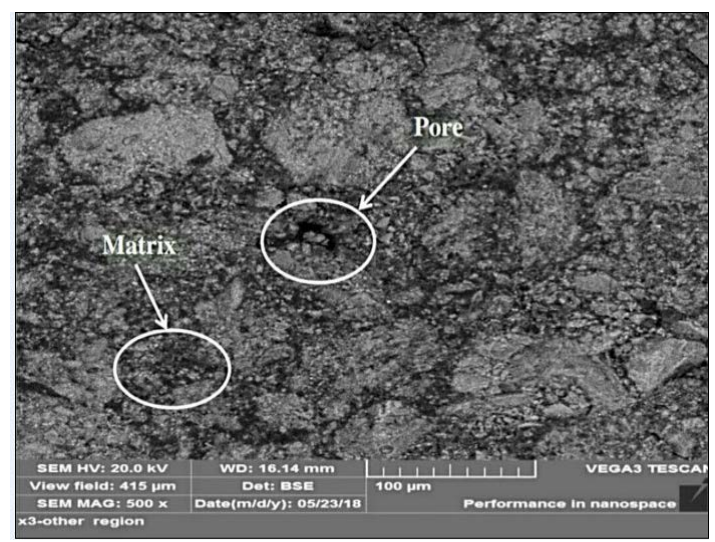

Fig. 3a, b): These SEM photos of the worn surface of brick composites specimens under room temerature

$$
\text { Wear rate }=\frac{\Delta \mathrm{w}}{\mathrm{SD}}(\mathrm{g} / \mathrm{cm})
$$

Where:

$\Delta \mathrm{w}=$ The weight difference $(\mathrm{g})$

$\mathrm{SD}=$ The Sliding Distance $(\mathrm{cm})$

Hardness shore D: The material hardness was measured by using shore D tester according to ASTM D 2240 by pressing the tip of the instrument on the specimen. The hardness was found by taking three readings on each face of the cylindrical specimen. The test was done after cleaning the specimens to ensure precise reading by the tester. By taking the average of the readings the hardness was obtained.
Worn surface morphology: The elemental composition and the morphology of worn surfaces were studied using analysis via. Scanning Electron Microscopy/ Energy Dispersive X-ray Spectroscopy (SEM/EDS), the surfaces of composites were coated with a conductive gold layer. SEM analysis in Fig. 2 and 3 give a good understanding of the wear mechanism, the effect of homogeneity of the matrix-grits and the pore content effect. The EDX analysis (Fig. 4) of the surface of specimens showed a very good combination of the elemental distribution. The determined concentration of the elements in the specimens indicated that a minimum amount of impurities in the waste. 
(a)

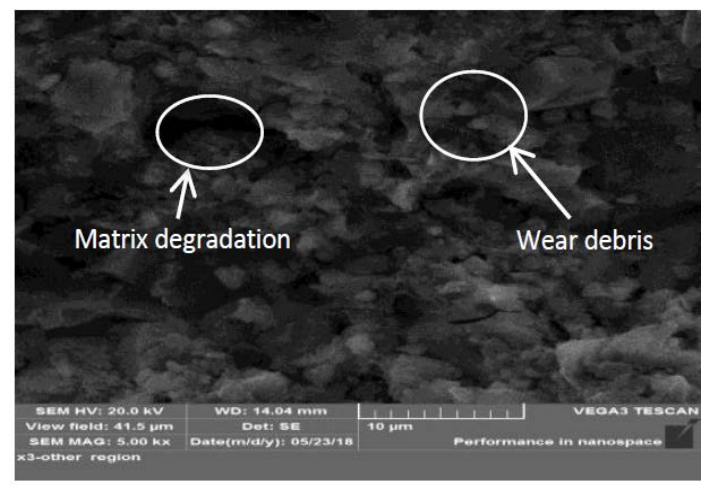

(b)

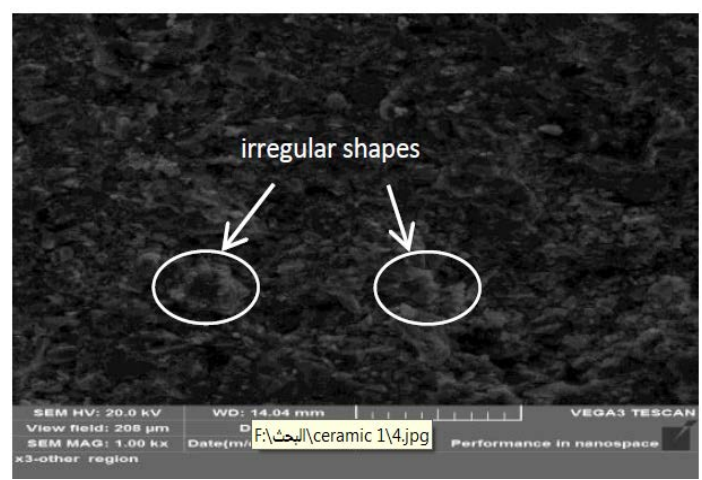

Fig. 4a, b): These SEM photos of the worn surface of brick tile composites specimens under room temerature

\section{RESULTS AND DISCUSSION}

In this study, the wear rate and hardness of the specimens were measured under four conditions. Which were post cured at $70^{\circ} \mathrm{C}$ for $2 \mathrm{~h}$, immersion for 14 days in distilled water and the two conditions, i.e., post curing and immersion together compared with specimens at room temperature. Abrasive materials are hard and resist the abrading action under different conditions, the most favourable materials have a high hardness and a low wear rate (Sureshkumar and Anilkumar, 2014; Mitchell, 2004).

The first group was tested at room temperature, this group showed high hardness results (Fig. 5 and 6) as well as the lowest wear rate (Fig. 7 and 8). The main cause is the good homogeneity and evenly distribution of epoxy on the surface in addition to the distribution of grits in all direction (Fig. 3 and 4). In general as the hardness increased the wear rate decreased (Swamy et al., 2010). The highest hardness values for the specimens was observed at the post-curing condition. Since, post-curing makes the epoxy significantly strong through, the formation of well cross-linked polymer networks increases the hardness (Yousif, 2010; Kumar et al., 2015). But the grits must retain their hardness during the test as the frictional heat lowered the hardness, post-curing producing a residual stress in epoxy these stress lead to give rise to severe plastic deformations all of this increase the wear rate (Marinescu et al., 2004). In the third group a noticeable higher increase in wear rate is observed after immersion in water. The water diffuse to epoxy cause it to swell which weakening the bonding properties of epoxy. Deboning of grits on the surface increasing the wear debris contributing to higher wear rates. The hardness values also reduced, the absorb of the water at the surface affect the mechanical properties leading to drop in hardness (Yousif, 2010). The fourth group had been

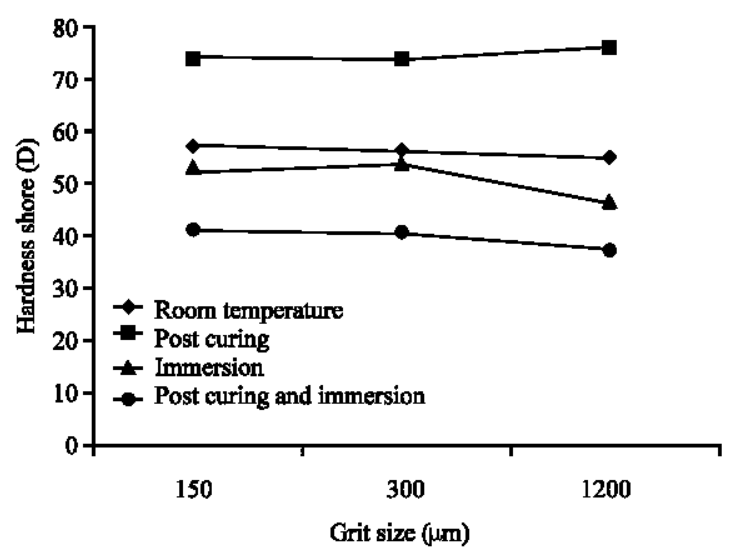

Fig. 5: Hardness for brick composites under different conditions

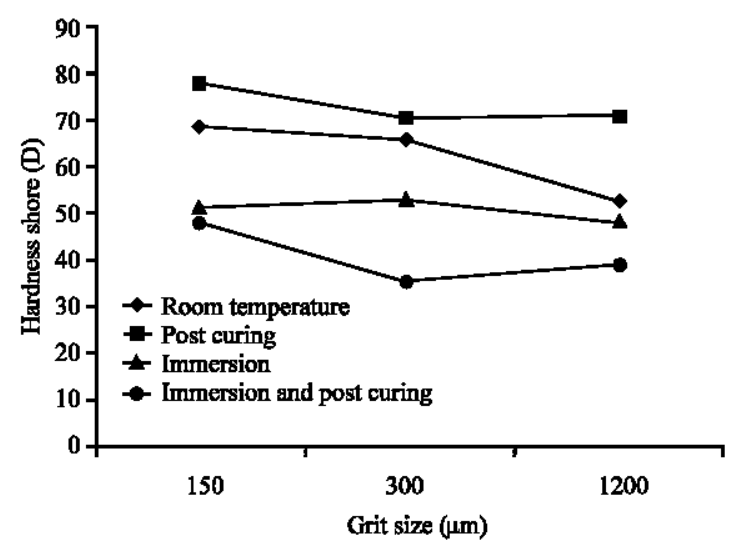

Fig. 6: Hardness for ceramic tile composites under different conditions

post-cured first followed by immersion is shows the lowest hardness and wear rate results compared to the other conditions. The syndromic effect the two conditions lead to severe degradation in the properties of the 


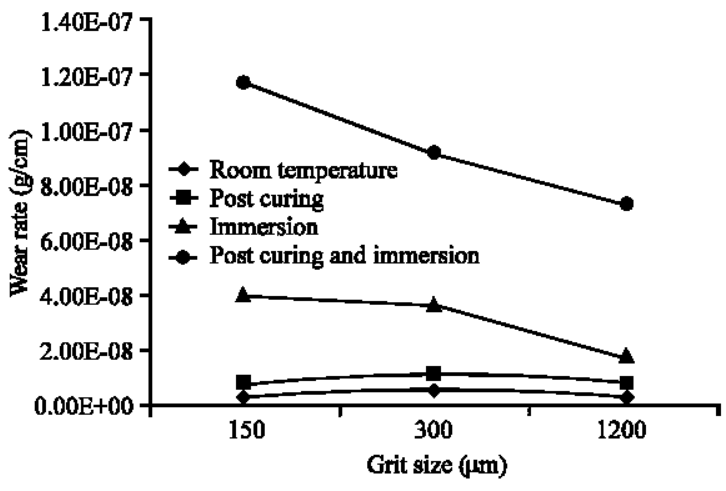

Fig. 7: Wear rate for brick composites under different conditions

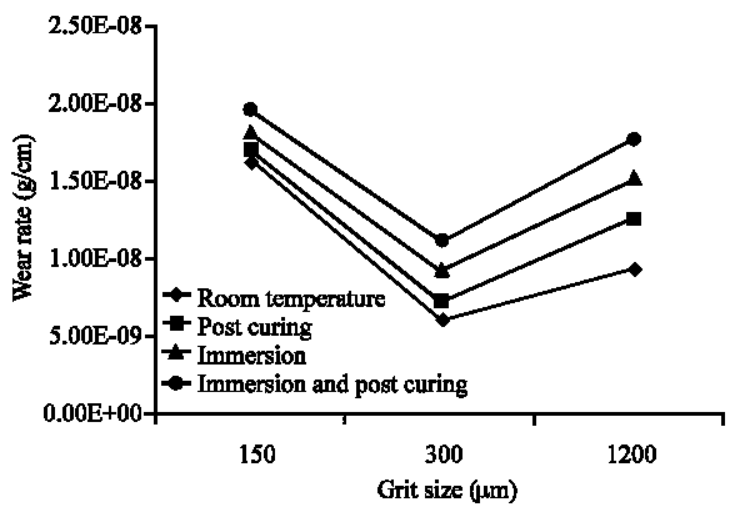

Fig. 8: Wear rate for glazed ceramic tile composites under different conditions

specimens. As for materials, the glazed ceramic tiles composites of $300 \mu \mathrm{m}$ grit size possess the with lower values of wear because of the homogeneity in the composite body and the high density (Fig. 4) which give closer pack that also attributed to the increase in hardness (Yawas et al., 2016). For the brick composites, the wear rate difference for the grit sizes is minimized as a result from good bonding between matrix-grits, the low pore content as shown in Fig. 3. Thermal stability of brick help to reducing the effect the frictional heat generated at the contact surface.

\section{CONCLUSION}

Both composites of glazed ceramic tiles and brick waste possess good properties for an abrasive. The glazed ceramic tiles composite have lower wear rate and higher hardness than brick composites. The best results were shown for glazed ceramic tile composite with $300 \mu \mathrm{m}$ grit size. The different conditions have slight effect on wear and hardness. The post cure and immersion together condition cause a sharp drop in the properties for the two composites. Whilst the room temperature results offered the highest degree of the desired properties with best hardness and wear rate compared to other conditions.

\section{REFERENCES}

Awange, J.L. and J.B.K. Kyalo, 2013. Environmental Geoinformatics: Monitoring and Management. Springer, Berlin, Germany, ISBN:978-3-642-34085-7, Pages: 541.

Ay, N. and M. Unal, 2000. The use of waste ceramic tile in cement production. Cement Concrete Res., 30: 497-499.

Bhowmik, S. and R. Naik, 2018. Selection of abrasive materials for manufacturing grinding wheels. Mater. Today Proc., 5: 2860-2864.

Demir, I. and M. Orhan, 2003. Reuse of waste bricks in the production line. Build. Environ., 38: 1451-1455.

El-Hofy, H.A.G., 2013. Fundamentals of Machining Processes: Conventional and Nonconventional Processes. 2nd Edn., CRC Press, Boca Raton, Florida, USA., ISBN:9781466577039, Pages: 562.

Kulovana, T., E. Vejmelkova, J. Pokorny, J.A. Siddique and M. Keppert et al., 2016. Engineering properties of composite materials containing waste ceramic dust from advanced hollow brick production as a partial replacement of Portland cement. J. Build. Phys., 40: 17-34.

Kumar, D.S., M.J. Shukla, K.K. Mahato, D.K. Rathore and R.K. Prusty et al., 2015. Effect of post-curing on thermal and mechanical behavior of GFRP composites. IOP Conf. Ser. Mater. Sci. Eng., 75: $1-6$.

Marinescu, I.D., W.B. Rowe, B. Dimitrov and I. Inaski, 2004. Tribology of Abrasive Machining Processes. Noyes Publication, New York, USA., ISBN:0-81551490-5, Pages: 723.

Martin, J., 2006. Materials for Engineering. 3rd Edn., Woodhead Publishing, Cambridge, UK., ISBN:9781845691608, Pages: 256.

Mitchell, B.S., 2004. An Introduction to Materials Engineering and Science for Chemical and Materials Engineers. John Wiley and Sons, Hoboken, New Jersey, USA., Pages: 961.

Obot, M.U., D.S. Yawas and S.Y. Aku, 2017. Development of an abrasive material using periwinkle shells. J. King Saud Uni. Eng. Sci., 29: 284-288.

Rambaldi, E., L. Esposito, A. Tucci and G. Timellini, 2007. Recycling of polishing porcelain stoneware residues in ceramic tiles. J. Eur. Ceram. Soc., 27: 3509-3515. 
Sekar, T., N. Ganesan and N. Nampoothiri, 2011. Studies on strength characteristics on utilization of waste materials as coarse aggregate in concrete. Intl. J. Eng. Sci. Technol., 3: 5436-5440.

Shumyacher, V.M., O.I. Pushkarev and A.V. Slavin, 2017. Energy efficient technology of obtaining advanced composite grinding materials and tools in Silicon Carbide-Corundum system from Aluminiumcontaining residual products. Procedia Eng., 206: 228-231.

Silvestre, R., E. Medel, A. Garcia and J. Navas, 2013. Utilizing recycled ceramic aggregates obtained from tile industry in the design of open graded wearing course on both laboratory and in situ basis. Mater. Des., 50: 471-478.

Sureshkumar, M.V. and P. Anilkumar, 2014. Engineering Chemistry-II. Vikas Publishing House Pvt Ltd, New Delhi, India, ISBN: 978-9325-976139,.

Swamy, N.P.R., C.S. Ramesh and T. Chandrashekar, 2010. Effect of heat treatment on strength and abrasive wear behaviour of $\mathrm{Al} 6061-\mathrm{SiC}_{\mathrm{p}}$ composites. Bull. Mater. Sci., 33: 49-54.
Taherzadeh, M.J. and T. Richards, 2015. Resource Recovery to Approach Zero Municipal Waste. CRC Press, Florida, USA., ISBN:9781482240368, Pages: 359.

Williams, P.T., 2005. Waste Treatment and Disposal. 2nd Edn., Wiley \& Sons, New Jersey, USA., ISBN-13:9780470849132, Pages: 392.

Yawas, D.S., S.Y. Aku and S.G. Amaren, 2016. Morphology and properties of periwinkle shell asbestos-free brake pad. J. King Saud Univ. Eng. Sci., 28: 103-109.

Yousif, B.A., 2010. Development and characterization of ternary thermosetting polymer blends. Ph.D Thesis, University of Technology Department of Applied Sciences, Baghdad, Iraq.

Zimbili, O., W. Salim and M. Ndambuki, 2014. A review on the usage of ceramic wastes in concrete production. Intl. J. Civ. Environ. Struct. Constr. Archit. Eng., 8: 91 95. Awange, J.L. and J.B.K. Kyalo, 2013. Environmental Geoinformatics: Monitoring and Management. Springer, Berlin, Germany, ISBN:978-3642-34085-7, Pages: 541. 